\title{
THE LANCET RELIEF FUND.
}

For Members of the Medical Profession and their Widows

and Orphans when in Distress.

- $: 0:-$

ALMONERS.

THE PRESIDENT OF THE ROYAL COLLEGE OF PHYSICIANS OF LONDON. THE PRESIDENT OF THE ROYAL COLLEGE OF SURGEONS OF ENGLAND. THE PRESIDENT OF THE GENERAL MEDICAL COUNCIL.

THOMAS WAKLEY, F.R.C.S. Eng.

THOMAS WAKLEY, Jun., L.R.C.P. Lond.

HON. AUDITOR.

SIR HENR P P TMAN, M.D. Camb, F.R.C.P.

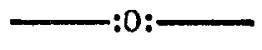

THIs Fund will be provided year by year in the month of January to the amount of at least $£ 300$ solely by the Proprietors of THe LANCET, and administered free of cost, for the purpose of affording immediate pecuniary assistance to Medical Men, or their Widows and Orphans, in cases of Acute Distress and Emergency, by the grant of money by way of loans free of interest, or gifts, as the circumstances of the various cases may require.

Applicants must satisfy the Almoners of the Fund that they are qualified under the following regulation :-

* "The recipients shall be such persons as satisfy the Almoners that they possess one or other of the following qualifications-that is to say : $(\alpha)$ That the applicant holds a registered medical qualification, and that he has fallen into pressing need of immediate pecuniary relief; or $(b)$ That they are persons who have been, previously to the date of application, legitimately dependent upon some person holding a registered medical qualification, and that they have pressing need of immediate pecuniary relief."

(In the case of Widons and Orphans, in order to come within the scope of the Fund, the death of the Husband or Father must have been of recent occurrence.)

To ensure the utmost despatch, the "Application Form" upon the other side should be filled up and forwarded (in an envelope superscribed "The LANCET Relief Fund") to the Secretary, Mr. Edward Davies, The Lancet Offices, Strand, London, W.C.

The application should be accompanied by two separate testimonials, one from the Clergyman of the Parish or other resident Minister of religion, and one from a registered Medical Practitioner, stating - that the application addressed to the Almoners has been read, how long they have known the applicant, and that they believe the statement to be perfectly truthful, and such as may be acted upon without further inquiry. 


\section{Private and Confidential.}

\section{APPLICATION FORM.}

\section{To the Almoners of the Lancet Relief Fund.}

The applicant should here state shortly :-

1. The nature of the emergency that has arisen.

2. The circumstances out of which it has arisen.

3. The amount of the grant desired, and whether by way of loan (free of interest) or of gift.

4. If by way of loan, state when the loan will be repaid; and from what source the funds to repay it are expected to be forthcoming. 
5. Whether the applicant is entitled or able in the circumstances which have arisen to look to any other source of assistance ; and if so, what is the expected nature and extent of such assistance.

6. Whether the applicant is receiving, or has received during the past six months, pecuniary aid from any Medical Charity.

7. State how the applicant is qualified to receive assistance ; vide regulation* on first page.

8. Particulars of :

Applicant's age

Number in family

How many are self-supporting

How many are partially dependent.

How many wholly dependent

Applicant's Signature

Address 


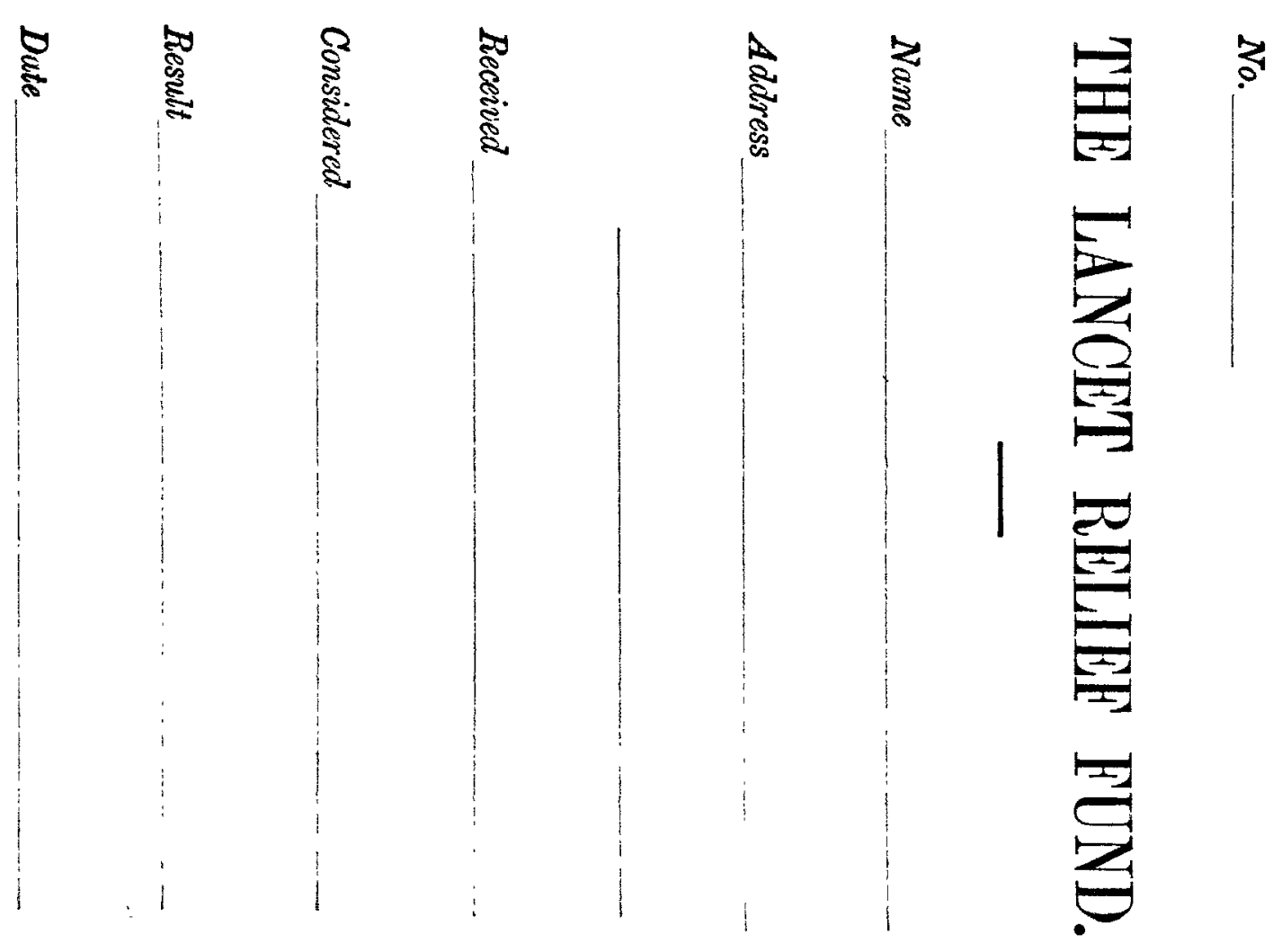

